Case Report

\title{
Use of Extracorporeal Membrane Oxygenation in Patients with Refractory Cardiac Arrest due to Severe Persistent Hypothermia: About 2 Case Reports and a Review of the Literature
}

\author{
Rachid Attou, ${ }^{1}$ Sébastien Redant, ${ }^{1}$ Thierry Preseau, ${ }^{2}$ Kevin Mottart, ${ }^{3}$ Louis Chebli, ${ }^{3}$ \\ Patrick M. Honore, ${ }^{1}$ David De Bels $\mathbb{1},{ }^{1}$ and Andrea Gallerani ${ }^{1}$ \\ ${ }^{1}$ Department of Intensive Care Medicine, Brugmann University Hospital, Brussels, Belgium \\ ${ }^{2}$ Emergency Department, Brugmann University Hospital, Brussels, Belgium \\ ${ }^{3}$ Department of Vascular Surgery, Brugmann University Hospital, Brussels, Belgium \\ Correspondence should be addressed to David De Bels; david.debels@chu-brugmann.be
}

Received 26 January 2021; Accepted 21 October 2021; Published 5 November 2021

Academic Editor: Aristomenis K. Exadaktylos

Copyright (c) 2021 Rachid Attou et al. This is an open access article distributed under the Creative Commons Attribution License, which permits unrestricted use, distribution, and reproduction in any medium, provided the original work is properly cited.

We report the cases of two patients experiencing persistent severe hypothermia. They were 45 and 30 years old and had a witnessed cardiac arrest managed with mechanized cardiopulmonary resuscitation (CPR) for 4 and 2.5 hours, respectively. Extracorporeal membrane oxygenation was used in both patients who fully recovered without any neurological sequelae. These two cases illustrate the important role of extracorporeal CPR (eCPR) in persistent severe hypothermia leading to cardiac arrest.

\section{Introduction}

Hypothermia is defined as a core temperature below $35^{\circ} \mathrm{C}$. Management of severe hypothermia associates rehydration and rewarming after having retrieved the patient from his cold environment [1]. Rehydration usually consists in perfusion of warmed $\left(42^{\circ} \mathrm{C}\right)$ isotonic fluids. Combinations of rewarming also include forced warm air, warm infusions, forced peritoneal lavage, or hemofiltration [2]. More recently, venoarterial extracorporeal membrane oxygenation (ECMO) has been the method of choice for in-hospital rewarming in severe hypothermia.

Cardiac arrest is frequent in severe hypothermia. Observational studies suggest that extracorporeal cardiopulmonary resuscitation can be associated with improved survival in very selected patients experiencing cardiac arrest even though randomized controlled trials are lacking [3, 4]. Out-of-hospital cardiac arrests are always associated with less favorable outcomes [5]. We would like to report two young patients with severe hypothermia and refractory long-lasting cardiac arrest treated by extracorporeal membrane oxygenation technique.

\section{Cases Reports}

The first patient, a 45-year-old Caucasian male, was found unconscious in a park this winter. Emergency medical services started cardiopulmonary resuscitation (CPR) on arrival. First rhythm was ventricular fibrillation. The patient received 4 inefficient defibrillation attempts and received a total of $4 \mathrm{mg}$ of epinephrine after asystole appeared. Core temperature was $22.7^{\circ} \mathrm{C}$ on a low-reading thermometer. Main medical history was chronic alcohol abuse. The patient was homeless. On hospital arrival, the patient was put under a Lund University Cardiac Arrest System (LUCAS ${ }^{\circledR}$ ) while awaiting the ECMO team. Admission arterial gas analysis showed a severe mixed acidosis associated with hypoxia: $\mathrm{pH} 6.98, \mathrm{PaCO}_{2}$ 57, and $\mathrm{PaO}_{2}$ 49. Laboratory testing showed anemia with $\mathrm{Hb} 9.8 \mathrm{~g} / \mathrm{dL}$ (13-18), a thrombocytopenia at $65000 / \mathrm{mm}^{3}(150-440000)$, and leucopenia with a total white 
cell count of $2470 / \mathrm{mm}^{3}$ (3.5-11). Coagulation disorders were also present. Admission ethanol was $2.4 \mathrm{~g} / \mathrm{L}$. No liver cytolysis or cholestasis was seen. The patient was transferred to the Intensive Care Unit. A venoarterial extracorporeal membrane oxygenation system was installed 110 minutes after hospital arrival (flow $1.8 \mathrm{~L} / \mathrm{min} / \mathrm{m}^{2}, \mathrm{FiO}_{2} 100 \%$ with femorofemoral approach including a $25 \mathrm{~F}$ venous catheter and a $19 \mathrm{~F}$ arterial catheter. The total time of CPR was 4.0 hours. Unfractionated heparin was given to keep anti-Xa between 0.5 and $0.7 \mathrm{IU} / \mathrm{mL}$ ). At $33^{\circ} \mathrm{C}$, a new defibrillation resulted in the appearance of a regular sinus rhythm. The patient was under mechanical ventilation as from admission on a volume control basis with a tidal volume of $420 \mathrm{~mL}, 20$ times per minute with at first an $\mathrm{FIO}_{2}$ of $100 \%$ then after VA ECMO and return to sinus rhythm after correction of hypothermia; the $\mathrm{FiO}_{2}$ was decreased to $40 \%$ in order to maintain $\mathrm{SpO}_{2}$ at $95 \%$. Pulmonary infection with $\mathrm{H}$. influenzae led to antimicrobial therapy by amoxiclav for 5 days. Seeing the total cardiovascular recuperation, ECMO was weaned on day 4 by the surgical team. Thorough neurological examination was done on days 3, 5, and 6 with good results. The patient was extubated on day 6 . He left the ICU on day 7 and the hospital on day 14 without any neurological sequelae.

The second patient, a 30-year-old Caucasian male, was admitted this winter to our Emergency Department with severe hypothermia. Main medical history was also chronic alcohol abuse. The patient was again homeless. Clinical examination revealed profound hypotension $(77 / 42 \mathrm{mmHg})$, bradycardia $(50 \mathrm{bpm})$, and coma (Glasgow coma scale E2, V2, and M2). Core temperature was $25.3^{\circ} \mathrm{C}$. The arterial blood gas analysis showed a severe acidosis with a $\mathrm{pH}$ of 6.95 , a $\mathrm{PaCO}_{2}$ of $26 \mathrm{mmHg}$, and hyperoxia at 155 . Lactic acidosis was present with a first value of $20 \mathrm{mmol} / \mathrm{L}(<2)$ as well as a severe anemia with $\mathrm{Hb} 3 \mathrm{~g} / \mathrm{dL}$ (13-18). Concentrated red blood cells were administered to maintain $\mathrm{Hb}$ above $8.5 \mathrm{~g} / \mathrm{L}$. Passive and active warming were started with forced hot air and warmed normal saline perfusions. Cerebral CT excluded any important ischemic stroke or intracerebral hemorrhage. Injected multiple phase abdominal CT excluded internal bleeding. Persistent coma led to intubation and mechanical ventilation with volume control with a tidal volume of $400 \mathrm{~mL}, 20$ times per minute with again at first an $\mathrm{FiO}_{2}$ of $100 \%$ then after VA ECMO and after correction of hypothermia and anemia; the $\mathrm{FiO}_{2}$ was decreased to $45 \%$ in order to maintain $\mathrm{SpO}_{2}$ at $95 \%$. The total CPR was finally 2.5 hours. Upon Intensive Care Unit arrival, the patient developed a cardiac arrest with ventricular fibrillation. Three defibrillation attempts failed to restore ROSC. No epinephrine was administered. Mechanized CPR was started with a LUCAS $^{\circledR}$ device, and the ECMO team was called. A venoarterial extracorporeal membrane oxygenation system was installed (flow $2 \mathrm{~L} / \mathrm{min} / \mathrm{m}^{2}, \mathrm{FiO}_{2} 100 \%$ with femorofemoral approach with a $25 \mathrm{~F}$ venous catheter and a $17 \mathrm{~F}$ arterial catheter). This permitted to achieve a full flow after 150 minutes. Unfractionated heparin was given with anti-Xa kept between 0.5 and $0.7 \mathrm{IU} / \mathrm{mL}$. At $30^{\circ} \mathrm{C}$, the defibrillation attempt was successful as in the first patient. The ECMO was weaned on day 3 , and the patient was extubated the next morning. Pulmonary infection with oxacillin-sensitive Staphylococcus aureus was treated for 7 days with flucloxacillin. He was transferred to a normal ward on day 6 to assess the exact nature of the anemia. A full digestive endoscopy including the upper part by esophagogastroduodenoscopy and the lower part with a full colonoscopy did not show any active or sequelae of bleeding. He left our hospital on day 11 with full neurological recovery. Figure 1 shows the first $24 \mathrm{~h}$ trend of temperature in these two patients.

\section{Discussion}

Hypothermia has been divided into 5 groups according to its severity (Table 1) [6]. If correctly treated, cardiac arrests linked to severe hypothermia seem to have good long-term prognosis [7]. Indeed, exceedingly long reanimated cardiac arrest with profound hypothermia has been observed to survive without neurological sequelae [8]. CPR should be withheld in hypothermic patients only if the cause of cardiac arrest is clearly attributable to a lethal injury, fatal illness, or prolonged asphyxia or if the chest is incompressible [9]. Usual signs of death as fixed mydriasis and rigor mortis are not easily applicable to hypothermic patients so deciding to start or withhold CPR is challenging [6]. Identifying noflow and low-flow times are crucial for prognosticating the success of CPR or eCPR. No-flow should be below 5 minutes and low-flow time beneath 100 minutes. No-flow time is rarely available in out-of-hospital hypothermia-induced cardiac arrest. A surrogate to minimally preserved metabolic activity could be end-tidal $\mathrm{CO}_{2}\left(\mathrm{ETCO}_{2}\right)$. An $\mathrm{ETCO}_{2}$ above $20 \mathrm{mmHg}$ could be a sign of relatively short no-flow time [10]. In 2013, the American Heart Association recommended $\mathrm{ETCO}_{2}$ as the primary physiological metric during $\mathrm{CPR}$ when neither an arterial nor a central venous catheter was in place and suggested titrating CPR performance to a goal $\mathrm{ETCO}_{2}$ of $>20 \mathrm{mmHg}$ [11]. The European Resuscitation Council (ERC) 2015 guidelines suggest using a waveform capnography to assess the quality of CPR but did not provide a specific $\mathrm{ETCO}_{2}$ target for resuscitation [12].

A literature-derived algorithm is summarized in Figure 2. Evaluation should include core temperature, serum potassium levels (crf. infra), age, comorbidities, and signs of prearrest asphyxia. If CPR is started, epinephrine administration should not be given under $30^{\circ} \mathrm{C}$ as it may cause myocardial injury [9]. If defibrillation is undertaken, there should be no more than 3 attempts. Rewarming speed is dependent on the technique used. Active external rewarming usually increases core temperature by 0.1 to $3^{\circ} \mathrm{C}$ per hour, whereas peritoneal lavage, thoracic lavage, or hemodialysis increases core temperature by $1-3,3$, and $2-4^{\circ} \mathrm{C} / \mathrm{h}$, respectively [13]. ECMO increase core temperature by $4^{\circ} \mathrm{C}$ per hour [14]. Optimal rewarming speed is ill-defined in the literature. A proposed maximum speed of $4^{\circ} \mathrm{C} / \mathrm{h}$ has been proposed [15] while maintaining a temperature gradient between patient and ECMO of maximum $10^{\circ} \mathrm{C}$ [16]. An animal study performed on a pig model compared two ECMO flow regimes $(1.5 \mathrm{~L} / \mathrm{min}$ vs. $3 \mathrm{~L} / \mathrm{min})$ and two different temperature goals ( 5 degrees Celsius above body temperature versus 38 degrees Celsius throughout the resuscitation). 


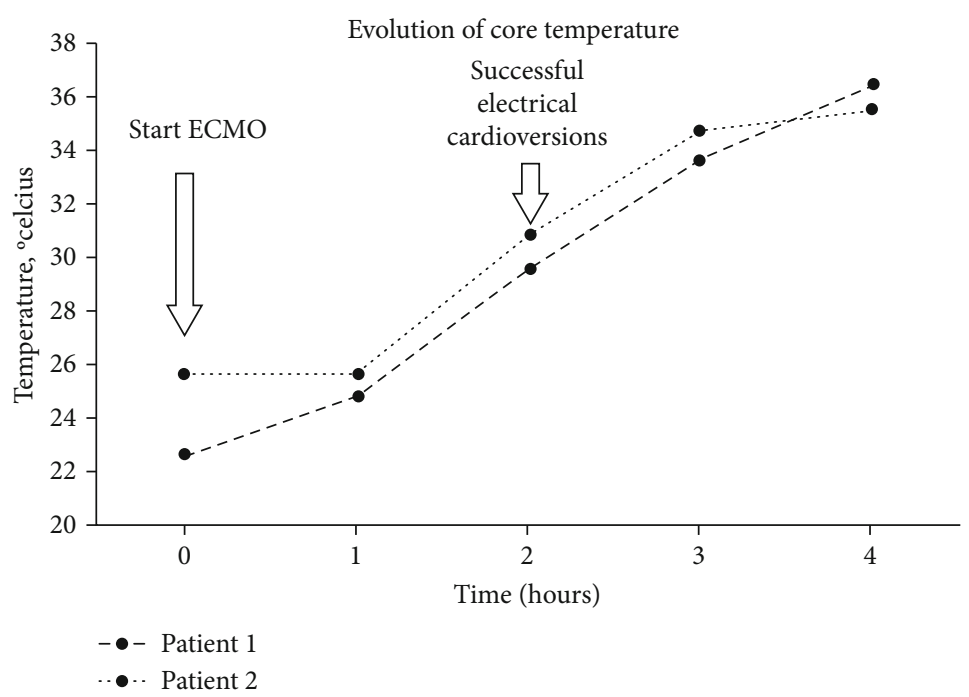

Figure 1: First 4-hour temperature trends in patients 1 and 2.

TABLE 1: Groups of hypothermia according to its severity [6].

\begin{tabular}{lccc}
\hline & Type & Temperature & Symptoms \\
\hline Group 1 & Mild & $35-32^{\circ} \mathrm{C}$ & Conscious, shivering patient \\
Group 2 & Moderate & $32-28^{\circ} \mathrm{C}$ & $\begin{array}{c}\text { Impaired consciousness without shivering } \\
\text { Group 3 }\end{array}$ \\
Severe & $28-24^{\circ} \mathrm{C}$ & $\begin{array}{c}\text { Coma, unconsciousness, present vital signs, possibility of } \\
\text { rhythm disturbance, bradycardia, wide QRS, and cardiac arrest }\end{array}$ \\
Group 5 & Very severe & Below $24^{\circ} \mathrm{C}$ & Cardiac arrest or low flow state \\
\hline
\end{tabular}

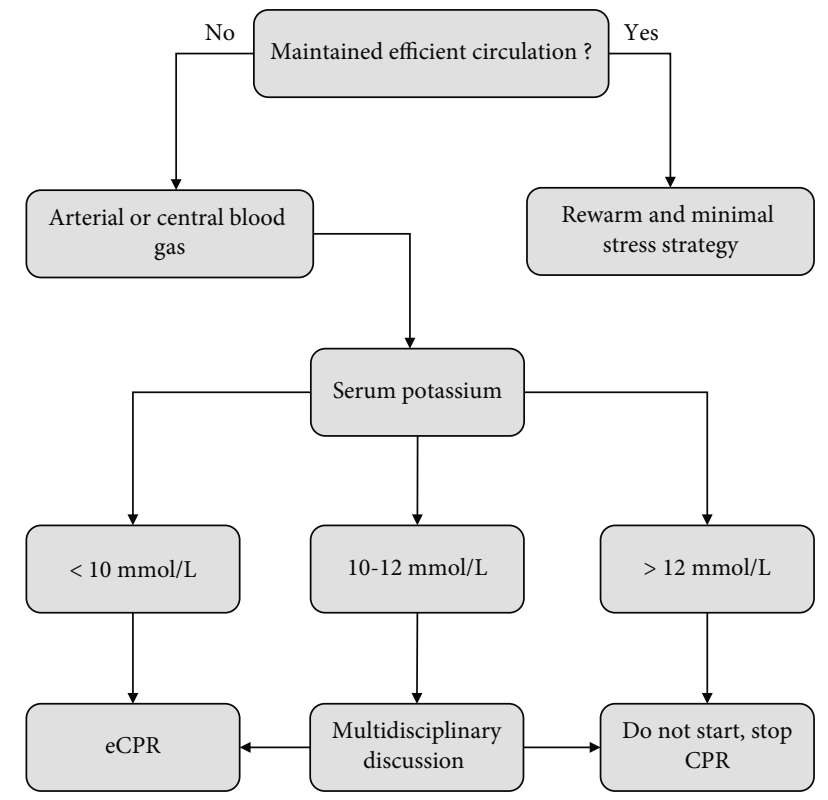

FIGURE 2: Decisional algorithm to start CPR in patients with severe hypothermia. Multidisciplinary discussion should include patient's age, comorbidities, time of no flow and/or low flow, presence of severe trauma, or prearrest signs of asphyxia.

They observed better cardiac output in the $3 \mathrm{~L} / \mathrm{min}$ group. Regarding temperature, the gradual warming by 5 degrees Celsius decreased the production of receptor for advanced glycation end products (RAGE) which is involved in the inflammatory cascade [16].

When core temperature is below $30-32^{\circ} \mathrm{C}$, another important factor for initiating CPR is serum potassium. Levels above $12 \mathrm{mmol} / \mathrm{L}$ are usually associated with poor outcome, and CPR should not be undertaken or should be terminated while under way (Figure 2). Between 10 and $12 \mathrm{mmol} / \mathrm{L}$, eCPR seems the best therapeutic choice and an ECMO team should be called. It is important here to weigh the awaited benefit of such a resource consuming therapy. Age, comorbidities, signs of prearrest asphyxia, or presence of severe trauma before starting an eCPR must be correctly evaluated. This is important because after trauma, patients will need anticoagulation during ECMO with the risk of severe bleeding. Below $10 \mathrm{mmol} / \mathrm{L}, \mathrm{CPR}$ should be continued until the patient is rewarmed [17]. It is important to have a correct sampling so that the result is reliable as decisions are definite. Below 8-10 mmol/L, CPR and eCPR should be initiated [18] even though a low potassium level does not guarantee survival [17]. Lactate and $\mathrm{pH}$ levels have very inconsistent in prognosticating outcome in hypothermiainduced cardiac arrest [19].

In a retrospective study on hypothermic patients accepted for extracorporeal rewarming at the Severe Accidental Hypothermia Center (Cracow), thirteen patients were identified with circulatory instability and were enrolled in the study. The evaluation took into account patients' 
condition on admission, the course of therapy, and changes in laboratory and hemodynamic parameters. Bad prognostic factors were identified: old age, low blood pressure on admission, low initial and postwarming $\mathrm{PaCO}_{2}$ partial pressure, low $\mathrm{pH}$, large base deficit, high serum creatinine, and potassium and lactate levels (marked at least six hours of rewarming) [20].

Recently, authors have studied a tool of hypothermia outcome prediction after extracorporeal life support for hypothermic cardiac arrest patients: the HOPE Score. In a population of 286 patients, 106 survived (37\%; 95\% CI: 32$43 \%)$, most (84\%) with a good neurological outcome. The final score developed after a multiple logistic regression model to predict survival included the following variables: age, sex, core temperature at admission, serum potassium level, mechanism of cooling, and cardiopulmonary resuscitation duration. The corresponding area under the receiver operating characteristic curve was 0.895 (95\% CI: 0.8590.931 ) compared to 0.774 (95\% CI: $0.720-0.828)$ when based on the serum potassium level alone [6].

Recently, a clinical case of a 27 -month-old boy who underwent accidental hypothermia to $11.8^{\circ} \mathrm{C}$ was published. $\mathrm{He}$ was resuscitated with prolonged rewarming by extracorporeal membrane oxygenation without significant neurological impairments. This is probably the lowest temperature ever documented, at which a human being has been successfully resuscitated from accidental hypothermia after a long period of circulatory arrest [21].

\section{Conclusion}

These two patients demonstrate the good prognosis of longlasting cardiac arrest due to severe hypothermia. ECMO is starting to be the treatment of choice after carefully evaluating the patients to ensure the benefit of such a resource consuming device. Evaluation should include core temperature, serum potassium levels, age, comorbidities, signs of prearrest asphyxia, or presence of severe trauma before starting an eCPR. Studies are necessary for providing strong recommendations in the management of severe hypothermia. In out of hospital cardiac arrest due to hypothermia, orientation to an ECMO center should be recommended.

\section{Consent}

The patients give their consent to publish.

\section{Conflicts of Interest}

The authors declare that they have no competing interests.

\section{Authors' Contributions}

RA, SR, AG, and DDB designed the paper. All authors participated in drafting and reviewing. All authors read and approved the final version of the manuscript.

\section{References}

[1] K. Zafren, G. G. Giesbrecht, D. F. Danzl et al., "Wilderness Medical Society practice guidelines for the out-of-hospital evaluation and treatment of accidental hypothermia: 2014 update," Wilderness \& Environmental Medicine, vol. 25, no. 4, pp. S66-S85, 2014.

[2] E. Gruber, W. Beikircher, R. Pizzinini et al., "Non-extracorporeal rewarming at a rate of $6.8{ }^{\circ} \mathrm{C}$ per hour in a deeply hypothermic arrested patient," Resuscitation, vol. 85, no. 8, pp. e119-e120, 2014.

[3] T. G. Shin, J. H. Choi, I. J. Jo et al., "Extracorporeal cardiopulmonary resuscitation in patients with inhospital cardiac arrest: a comparison with conventional cardiopulmonary resuscitation," Critical Care Medicine, vol. 39, no. 1, pp. 1-7, 2011.

[4] D. Stub, S. Bernard, V. Pellegrino et al., "Refractory cardiac arrest treated with mechanical CPR, hypothermia, ECMO and early reperfusion (the CHEER trial)," Resuscitation, vol. 86, pp. 88-94, 2015.

[5] G. Debaty, V. Babaz, M. Durand et al., "Prognostic factors for extracorporeal cardiopulmonary resuscitation recipients following out-of-hospital refractory cardiac arrest. A systematic review and meta-analysis," Resuscitation, vol. 112, pp. 1-10, 2017.

[6] M. Pasquier, N. Zurron, B. Weith et al., "Deep accidental hypothermia with core temperature below $24^{\circ} \mathrm{C}$ presenting with vital signs," High Altitude Medicine \& Biology, vol. 15, no. 1, pp. 58-63, 2014.

[7] B. H. Walpoth, B. N. Walpoth-Aslan, H. P. Mattle et al., "Outcome of survivors of accidental deep hypothermia and circulatory arrest treated with extracorporeal blood warming," The New England Journal of Medicine, vol. 337, no. 21, pp. 15001505, 1997.

[8] K. Lexow, "Severe accidental hypothermia: survival after 6 hours 30 minutes of cardiopulmonary resuscitation," Arctic Medical Research, vol. 50, Suppl 6, pp. 112-114, 1991.

[9] A. Truhlář, C. D. Deakin, J. Soar et al., "European Resuscitation Council Guidelines for Resuscitation 2015: Section 4. Cardiac arrest in special circumstances," Resuscitation, vol. 95, no. 95, pp. 148-201, 2015.

[10] C. Sandroni, P. de Santis, and S. D’Arrigo, "Capnography during cardiac arrest," Resuscitation, vol. 132, pp. 73-77, 2018.

[11] P. A. Meaney, B. J. Bobrow, M. E. Mancini et al., "Cardiopulmonary resuscitation quality: [corrected] improving cardiac resuscitation outcomes both inside and outside the hospital: a consensus statement from the American Heart Association," Circulation, vol. 128, no. 4, pp. 417-435, 2013.

[12] J. Soar, J. P. Nolan, B. W. Böttiger et al., "European Resuscitation Council Guidelines for Resuscitation 2015: Section 3. Adult advanced life support," Resuscitation, vol. 95, no. 95, pp. 100-147, 2015.

[13] N. Sultan, K. D. Theakston, R. Butler, and R. S. Suri, “Treatment of severe accidental hypothermia with intermittent hemodialysis," CJEM, vol. 11, no. 2, pp. 174-177, 2009.

[14] R. Tiruvoipati, S. K. Balasubramanian, E. Khoshbin, L. Hadjinikolaou, A. W. Sosnowski, and R. K. Firmin, "Successful use of venovenous extracorporeal membrane oxygenation in accidental hypothermic cardiac arrest," ASAIO Journal, vol. 51, no. 4, pp. 474-476, 2005.

[15] T. Darocha, A. Jarosz, M. Zietkiewicz et al., "ECMO in Treating Patients in Critical, Life-Threatening Medical Condition Brought on by Severe Hypothermia-Criterion Standard," 
Annals of Emergency Medicine, vol. 67, no. 4, pp. 558-559, 2016.

[16] G. Debaty, M. Maignan, B. Perrin et al., "Cardiopulmonary responses during the cooling and the extracorporeal life support rewarming phases in a porcine model of accidental deep hypothermic cardiac arrest," Scandinavian Journal of Trauma, Resuscitation and Emergency Medicine, vol. 24, no. 1, p. 91, 2016.

[17] M. Farstad, K. S. Andersen, M. E. Koller, K. Grong, L. Segadal, and P. Husby, "Rewarming from accidental hypothermia by extracorporeal circulation. A retrospective study," European Journal of Cardio-Thoracic Surgery, vol. 20, no. 1, pp. 58-64, 2001.

[18] P. Paal, L. Gordon, G. Strapazzon et al., "Accidental hypothermia-an update: the content of this review is endorsed by the International Commission for Mountain Emergency Medicine (ICAR MEDCOM)," Scandinavian Journal of Trauma, Resuscitation and Emergency Medicine, vol. 24, no. 1, p. 111, 2016.

[19] G. J. van der Ploeg, J. C. Goslings, B. H. Walpoth, and J. J. Bierens, "Accidental hypothermia: rewarming treatments, complications and outcomes from one university medical centre," Resuscitation, vol. 81, no. 11, pp. 1550-1555, 2010.

[20] S. Kosiński, T. Darocha, A. Jarosz et al., "Clinical course and prognostic factors of patients in severe accidental hypothermia with circulatory instability rewarmed with veno-arterial ECMO - an observational case series study," Scandinavian Journal of Trauma, Resuscitation and Emergency Medicine, vol. 25, no. 1, p. 46, 2017.

[21] T. Mroczek, M. Gladki, and J. Skalski, "Successful resuscitation from accidental hypothermia of $11.8^{\circ} \mathrm{C}$ : where is the lower bound for human beings?," European Journal of CardioThoracic Surgery, vol. 58, no. 5, pp. 1091-1092, 2020. 